\title{
La portada del Colegio de San Pedro y San Pablo de la Universidad de Alcalá de Henares (1799)
}

\author{
Miguel Ángel Nieto Márquez ${ }^{1}$ \\ Universidad de Sevilla
}

\section{RESUMEN}

El reinado de Carlos III supuso, dentro de la corriente modernizadora que protagonizó, la reforma de la Universidad de Alcalá de Henares, que afectó a los colegios menores de fundación cisneriana y otros, pero no al Colegio de San Pedro y San Pablo, que quedaría independiente bajo su orden franciscana. En 1799 surgió la necesidad de realizar una nueva portada de acceso a dicho colegio desde el exterior, evitándose así los daños e inconvenientes que se venían produciendo a causa de la entrada a través del antiguo Colegio Mayor. El presente artículo analiza las causas y el proceso de realización de dicha portada, la cual fue realizada por el arquitecto de la Universidad, Antonio Juana Jordán.

\section{PALABRAS CLAVE}

Colegio de San Ildefonso, Juan de Lucas y López, Julián Cabada, Pedro Carrasco, Ilustración.

The façade of the College of San Pedro and San Pablo of the University of Alcalá de Henares (1799)

ABSTRACT

The modernizing current of the reign of Carlos III supposed the reform of the University of Alcalá de Henares. This reform affected the minor colleges founded by Cardenal Cisneros, but the franciscan orden of the College of San Pedro and San Pablo continued independent. In 1799, this college needed a new façade to access from the outside to avoid the damage and inconveniences caused by the access located in the old college major. This article analyzes the causes and the contruction process of this façade, designed by Antonio Juana Jordán, the architect of the University.

\section{KEY WORDS}

College of San Ildefonso, Juan de Lucas y López, Julián Cabada, Pedro Carrasco, Enlightenment.

\footnotetext{
${ }^{1}$ Proyecto de Investigación PGC2018-099323-B-I00: Arquitecturas del poder en el Caribe y el Sudeste Asiático (1729-1764)
} 
A mediados del siglo XVIII, las corrientes ilustradas tomaron unas posiciones destacadas en la sociedad española. Con la subida al trono de Carlos III, se produjeron reformas en gran parte de las estructuras sociales, políticas, económicas y culturales del país, transformándose profundamente las universidades, y de una forma muy acusada la de Alcalá ${ }^{1}$. Se buscaba así la modernización y la reforma de las instituciones, así como el fin de un panorama corrupto en el que los hombres procedentes de los colegios mayores formaban una élite sin competencia que acaparaba una buena parte de los puestos administrativos y eclesiásticos de la Monarquía Católica, formando lo que ha venido a denominarse una "aristocracia académica". El encargado de llevar a cabo la reforma de la Universidad Complutense fue el cancelario y abad mayor de la Magistral D. Pedro Díaz de Roxas, incautando en 1776 los bienes y rentas del Colegio de San Ildefonso, e instituyéndose en nombre del rey como rector, cargo que ostentaría hasta 1781. Declararía separados Colegio Mayor y Universidad, emancipando esta del control colegial y dotándola del derecho a nombrar rector propio, que ya no sería de San Ildefonso ni podría ser colegial de él. Desde entonces la institución pasaría a llamarse Real Universidad de Alcalá, con sede en el antiguo Colegio Máximo jesuita reformado al efecto por Ventura Rodríguez, extinguiéndose más tarde el Colegio Mayor, a cuyo edificio se trasladó la Universidad en $1798^{2}$. La reforma en Alcalá no se limitó al Colegio Mayor, sino que afectó

\footnotetext{
Véase: DE LA FUENTE, Vicente, Historia de las Universidades, colegios y demás establecimientos de enseñanza en España, tomo 4, Imp. De la Viuda e Hija de Fuentenebro, Madrid, 1889, pp. 88-91 y 245-248. CALLEJA CARRASC0, José Demetrio, "Bosquejo histórico de los colegios seculares de la Universidad de Alcalá de Henares", en Revista Contemporánea, n. ${ }^{\circ}$ 116, Madrid, 1899, p. 652. JIMÉNEZ FRAUD, Alberto, Historia de la Universidad Española, Alianza, Madrid, 1971, pp. 271279 y 282-289. PESET, Mariano y PESET, José Luis, La Universidad española (Siglos XVIII y XIX). Despotismo ilustrado y revolución liberal, Taurus, Madrid, 1974, pp. 52-64, 107-113 y 333-349. ÁLVAREZ DE MORALES, Antonio, La Ilustración y la Reforma de la Universidad en la España del Siglo XVIII, INAP, Madrid, 1988.

2 ADDY, George M., "Alcalá before the Reform. The decadence of Spanish University", en The Hispanic American Historical Review, vol. 48, n. ${ }^{\circ}$ 4, Durham, 1968, p. 561.

ÁLVAREZ DE MORALES, Antonio, "El Colegio Mayor de San Ildefonso y la configuración del poder colegial", en Estudios de la Universidad, Pegaso, Madrid, 1993, pp. 29-37.
}

también a los colegios menores de fundación cisneriana y otros. En el caso del Colegio de San Pedro y San Pablo, que es el que nos ocupa, quedaría independiente bajo su orden franciscana $^{3}$, siendo el único que se mantuvo intacto ante la refundición de los otros colegios cisnerianos en el Colegio de la Purísima Concepción, creado en $1779^{4}$.

A D. Pedro Díaz de Roxas le sucedería D. Juan de Lucas y López, quien sería cancelario y arcipreste de Alcalá desde 1787 hasta su dimisión en $1799^{5}$. Precisamente, entre 1790 y 1793, el comisionado real había procedido a adecentar distintas salas de la universidad en su emplazamiento del antiguo colegio jesuita, y en 1795 dicho cancelario escribía una carta al rector de la institución académica comunicando las gestiones que había llevado a cabo para la realización de una sillería en la sala del claustro $^{6}$, una obra que supervisó D. Antonio

BALLESTEROS TORRES, Pedro, "Pedro Díaz de Rojas y las reformas de la Universidad de Alcalá en el siglo XVIII", en Ciclo de conferencias 2002. Institución de Estudios Complutenses, IEC, Alcalá de Henares, 2003, pp. 321-349.

GUTIÉRREZ TORRECILLA, Luis Miguel, "La reforma borbónica en la Universidad de Alcalá: cambios institucionales y académicos", en Historia de la Universidad de Alcalá, Universidad de Alcalá de Henares. Servicio de Publicaciones, Alcalá de Henares, 2010, pp. 459-488.

Sobre la intervención de Ventura Rodríguez, véase: T0VAR MARTÍN, Virginia, "Ventura Rodríguez y su proyecto de la nueva universidad en Alcalá de Henares", en Academia. Boletín de la Real Academia de Bellas Artes de San Fernando, n. ${ }^{\circ}$ 54, Madrid, 1982, pp. 185238.

TOVAR MARTÍN, Virginia, "El Colegio Máximo Complutense y sus edificios”, en La Compañia de Jesús en Alcalá de Henares (1546-1989), Institución de Estudios Complutenses, Alcalá de Henares, 1989, pp. 25-32. TOVAR MARTÍN, Virginia, "Aportaciones artísticas singulares en el marco 'histórico' de Alcalá de Henares”, en La Universidad de Alcalá, vol. II, Colegio Oficial de Arquitectos de Madrid y de la Universidad de Alcalá de Henares, Madrid, 1990, pp. 230-237.

TOVAR MARTÍN, Virginia, "Ventura Rodríguez: restauración y renovación de espacios universitarios de Alcalá", en Una Hora de España. VII Centenario de la Universidad Complutense, Universidad Complutense, Madrid, 1994, pp. 36-48.

3 URIBE, Ángel, Colegio y colegiales de San Pedro y San Pablo de Alcalá, Editorial Cisneros, Madrid, 1981, p. 59. GUTIÉRREZ TORRECILLA, Luis Miguel, "La reforma borbónica..., opus. cit., p. 462.

5 Véase: DIEGO PAREJA, Luis Miguel de, La expulsión de los jesuitas de Alcalá de Henares en 1767 y vicisitudes de sus propiedades hasta su regreso en 1827, Fundación Colegio del Rey, Alcalá de Henares, 1997, p. 164. 6 GONZÁlEZ RAMOS, Roberto y RUIZ CARRASCO, Jesús María, "La sillería de claustro de la real universidad 
Juana Jordán, el arquitecto de las obras de la Universidad $^{7}$, quien también se encargó de la portada que se trata en este artículo.

Sobre este arquitecto, procedente de Madrid al igual que su familia, se conoce que en 1777 se avecindó en Alcalá de Henares, presentándose al Ayuntamiento como arquitecto y maestro de obras, título que recibió del Arzobispado de Toledo. En ese mismo año, fue nombrado arquitecto mayor de la ciudad, mientras que en 1778 solicitó el nombramiento de fontanero mayor ${ }^{8}$. La Puerta de Madrid, erigida entonces en Alcalá a expensas del arzobispo de Toledo Francisco Antonio Lorenzana y bajo la supervisión de la Real Academia de San Fernando, es una de sus obras más conocidas, en la que como funcionario municipal demostró un correcto conocimiento de las proporciones y de los órdenes de la arquitectura clásica académica9 ${ }^{9}$. También en Alcalá se hizo cargo, entre otras reparaciones, de la reconstrucción de las Casas Consistoriales, de los Puentes Zulema y Torote y la cuesta

de Alcalá de Henares (1795-1796)", en Ars Longa, n. ${ }^{\circ}$ 25, Valencia, 2016, p. 181. https://dialnet.unirioja.es/ servlet/articulo? codigo $=5996908$ Ctorden $=0$ \&tinfo $=$ link Fecha de consulta: 08/05/2020.

AHN. Universidades. Libro 176, fol. 251v.

8 ROMÁN PASTOR, Carmen, "La Puerta de Madrid, un ejemplo de arquitectura academicista en Alcalá de Henares", en Actas del IV Encuentro de Historiadores del Valle de Henares, Instituto de Estudios Complutenses, Alcalá de Henares, 1994, p. 645.

CALLEJA CARRASCO, José Demetrio, "Bosquejo histórico... opus. cit., pp. 664-665.

Sobre Antonio Juana Jordán, cabe destacar su papel en 1783 cuando el maestro librero Gregorio Ramírez dio cuenta de las diferentes irregularidades existentes a la hora de realizar el inventario y la tasación de los bienes de la biblioteca del Colegio Máximo de la Compañía de Jesús. Véase: LÓPEZ ÁLVAREZ, Olga M.a ", "La situación de las bibliotecas de los colegios menores de Alcalá en el siglo XVIII", en Aulas y saberes: VI Congreso Internacional de Historia de las Universidades Hispánicas, vol. 2, Universitat de València, Valencia, 2003, pp. 106107.

9 Sobre esta obra, véase: ROMÁN PASTOR, Carmen, "La Puerta de Madrid... opus. cit., pp. 643-658.

LLUL PEÑALBA, Josué, "El derribo de la muralla de Alcalá de Henares en el siglo XIX", en Anales del Instituto de Estudios Madrileños, XLVI, Madrid, 2006, pp. 405 y 413.

https://www.researchgate.net/publication/292978497_ El_derribo_de_la_muralla_de_Alcala_de_Henares_en_ el_siglo_XIX Fecha de consulta: 08/05/2020.

MUÑOZ JIMÉNEZ, José Miguel, "La Iglesia parroquial de Ciruelas y su arquitecto Jesús Tadeo de la Plaza (a propósito del neoclasicismo en la provincia de Guadalajara), en Wad-al-Hayara: Revista de estudios de Guadalajara, n. ${ }^{\circ}$ 28, Guadalajara, 2001, p. 153. del Zulema ${ }^{10}$. En palabras de Muñoz Jiménez, el caso de Juana Jordán "es muy ilustrativo de las peripecias que sufrieron los maestros de obras a la hora de convalidar su formación con los títulos expedidos por la Real Academia”, especialmente tras la suspensión de los títulos otorgados por el Consejo y los Ayuntamientos mediante la Real Orden de 1787, adjudicándose esta competencia a las instituciones académicas ${ }^{11}$. Por ello, en 1788 nuestro personaje se volvió a examinar para obtener el certificado de maestro de obras por parte la Academia de San Fernando, siendo aprobado en la Junta Ordinaria el 4 de enero de 1789 tras la realización de los cuatro dibujos conservados en el museo de dicha institución, consistentes en el proyecto de dos plantas, dos cortes y la fachada de una casa para para un hacendado ${ }^{12}$. Más tarde, se tiene constancia del reconocimiento y la tasación que llevó a cabo junto al arquitecto Juan Antonio Cuerbo de la casa palacio del Soto de Aldovea, en San Fernando de Henares ${ }^{13}$, así como del proyecto que presentó para culminar la nueva iglesia parroquial de la villa de Uceda (Guadalajara) en 1791. Sin embargo, este no fue aprobado debido a los abusos que los maestros de obras examinados cometían al diseñar edificios de gran envergadura, de modo que los académicos señalaron que el proyecto respondía más a las facultades propias de un arquitecto $^{14}$. La portada que aquí se trata no pasó por el filtro académico, quizás por tratarse de una obra menor o porque su autor no solamente era uno de los maestros de obras de la academia, sino que lo era de una institución real, estatal y con un alto grado de autonomía en multitud de campos.

10 ROMÁN PASTOR, Carmen, "La Puerta de Madrid... opus. cit., p. 646.

11 MUÑOZ JIMÉNEZ, José Miguel, “La Iglesia parroquial... opus. cit., p. 153.

12 ROMÁN PASTOR, Carmen, "La Puerta de Madrid... opus. cit., p. 647.

ARBAIZA BLANCO-SOLER, Silvia y HERAS CASAS, Carmen, "Inventario de los dibujos arquitectónicos (de los siglos XVIII y XIX) en el Museo de la Real Academia de Bellas Artes de San Fernando (II)", en Boletín de la Real Academia de Bellas Artes de San Fernando, n. ${ }^{\circ}$ 92 y 93, Madrid, 2001, p. 159.

13 MARTÍNEZ MEDINA, África y SUÁREZ PERALES, Ana Isabel, "La casa palacio del Soto de Aldovea: estudio histórico artístico", en Anales del Instituto de Estudios Madrileños, n. ${ }^{\circ}$ 29, Madrid, 1990, p. 90.

14 ROMÁN PASTOR, Carmen, "La Puerta de Madrid... opus. cit., p. 646.

MUÑOZ JIMÉNEZ, José Miguel, “La Iglesia parroquial... opus. cit., p. 152. 
Así pues, Antonio Juana Jordán responde al perfil tópico de arquitecto clasicista convencido, racional, metódico, frío burócrata y fiel a la normativa convencional ${ }^{15}$. Con la llegada de los Borbones a comienzos del siglo XVIII, la arquitectura española sufrió un importante cambio, ya que los nuevos monarcas buscaban crear una nueva realidad afín a las otras cortes europeas frente al llamado "barroco castizo", rodeándose de arquitectos extranjeros, primero franceses y después italianos, junto a los que trabajaría un grupo de españoles con formación en Italia que en algunos casos llegarian a superar a dichos italianos. Esta modificación formal de la arquitectura no respondía solamente a un cambio de gusto, ya que también estaba ligada a unos nuevos intereses políticos tendentes a introducir en España las ideas de la Ilustración y una mayor eficacia en el gobierno a través de la centralización y del poder absoluto $^{16}$. Por tanto, con la fundación de la Real Academia de Bellas Artes de San Fernando en 1752, se intentó renovar el panorama artístico español mediante la implantación de un estilo académico y un lenguaje artístico similar al que venía utilizándose en Europa.

Arquitectos como Antonio Juana Jordán, con una formación académica completa, un equilibrio adecuado entre un aprendizaje teórico y otro práctico, y con un importantísimo conocimiento de la tratadística, usarían el dibujo como lenguaje específico del arte ${ }^{17}$, como se comprueba en la portada del Colegio de San Pedro y San Pablo. Para el fundamental conocimiento de la tratadística por parte de los alumnos de la Academia, la institución se preocupó de formar una biblioteca con las principales obras sobre las Bellas Artes españolas y extranjeras, reimprimiendo tratados escritos en espa-

15 Sobre la imagen tópica del arquitecto académico, véase GARCÍA MELERO, José Enrique, "El arquitecto académico a finales del siglo XVIII", en Espacio, tiempo y forma, serie VII, n. ${ }^{\circ}$ 10, Madrid, 1997, p. 163. http://e-spacio.uned.es/fez/eserv.php?pid=bibliuned:ETFSerie7-41493DC5-1686-C49A-D9C2-86B1C9B5607ACtdsID=Documento.pdf Fecha de consulta: 08/05/2020.

16 CAMACHO MARTÍNEZ, Rosario, "Arquitectos de la Academia de San Fernando en la Málaga del siglo XVIII", en Boletín de la Real Academia de Bellas Artes de San Fernando, n. ${ }^{\circ}$ 67, Madrid, 1988, p. 267. http://www.cervantesvirtual.com/obra-visor/arquitectos-de-la-academia-de-san-fernando-en-la-mlagadel-siglo-xviii-0/html/ Fecha de consulta: 08/05/2020.

17 GARCÍA MELERO, José Enrique, "El arquitecto... opus. cit., p. 164. ñol, traduciendo publicaciones imprescindibles $\mathrm{y}$ redactando sus propias obras ${ }^{18}$. De esta forma, los escritos de Vitruvio, Serlio, Scamozzi, Alberti o Palladio, serían fundamentales en la formación del nuevo arquitecto académico ${ }^{19}$.

\section{El Colegio de San Pedro y San Pablo}

El Colegio franciscano de San Pedro y San Pablo de Alcalá de Henares (Fig. 1) constituye una de las primeras fundaciones del Cardenal Cisneros en el magno proyecto universitario complutense, dirigida a dejar a su orden un centro unido a su academia, aunque con una viabilidad dudosa en lo referente a la orientación que le darían los superiores de la Observancia tras su fallecimiento ${ }^{20}$. Fue fundado para trece franciscanos ${ }^{21}$, un guardián, dos legos y un criado, y vivía de las rentas del Colegio Mayor de San Ildefonso, teniendo en 1526 inventariados su archivo, biblioteca, sacristía y otros bienes muebles, y en 1586 todas sus heredades, conociéndose además que desde 1550 guardaba el estatuto de limpieza de sangre ${ }^{22}$. Sobre su construcción aneja al Colegio de San Ildefonso $^{23}$ hay pocos datos, aunque ya en 1508 aparece en los documentos sobre obras, no estando aún terminado en la segunda mitad del año si-

18 SAMBRICIO, Carlos, "La arquitectura de la segunda mitad del siglo XVIII y los ideales de la razón”, en Juan de Villanueva, arquitecto (1739-1811), Ayuntamiento de Madrid, Delegación de Cultura, Madrid, 1982, pp. 3-31. http://oa.upm.es/10867/1/arquitecturasegundamitadsigloxviii.pdf Fecha de consulta: 08/05/2020.

19 GARCÍA MELERO, José Enrique, "El arquitecto... opus. cit., p. 172.

20 GONZÁLEZ RAMOS, Roberto, La Universidad de Alcalá de Henares y las Artes: el patronazgo artístico de un centro del saber, siglos XVI-XIX, Universidad de Alcalá de Henares, Servicio de Publicaciones, Alcalá de Henares, 2007, p. 59.

21 RUIZ RODRÍGUEZ, José Ignacio, “Las fundaciones de los colegios de la Universidad de Alcalá en el siglo XVI hasta las resoluciones tridentinas", en Historia de la Universidad de Alcalá, Universidad de Alcalá de Henares, Servicio de Publicaciones, Alcalá de Henares, 2010, p. 126.

22 CASADO ARBONIÉS, Manuel, "Los colegios menores seculares de patronato eclesiástico de la Universidad de Alcalá: líneas de investigación”, en Universidades clásicas de la Europa mediterránea: Bolonia, Coimbra y Alcalá, Universidad de Salamanca, Salamanca, 2006, p. 219.

23 RUIZ RODRÍGUEZ, José Ignacio, "Las fundaciones... opus. cit., p. 126. 


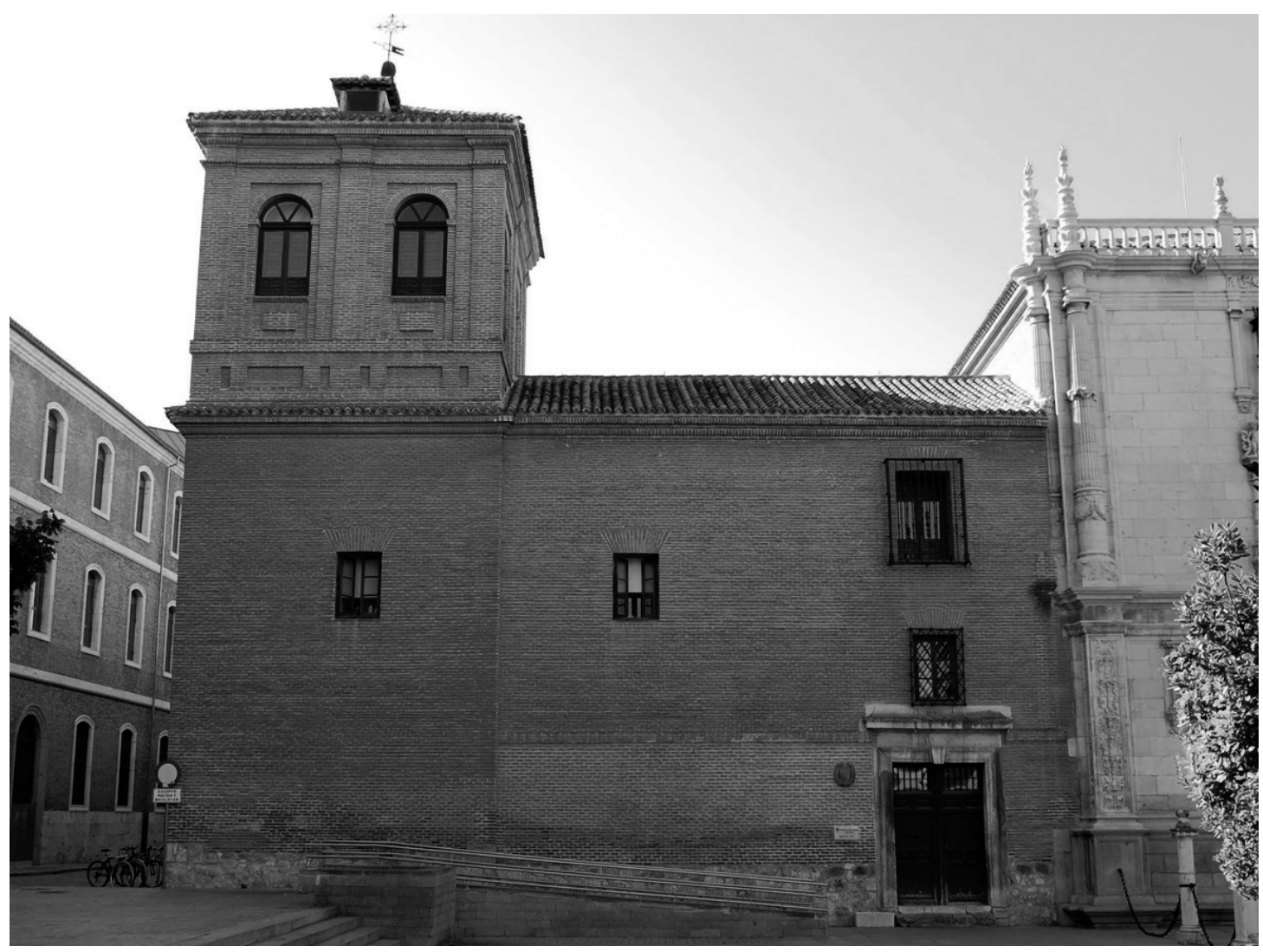

Fig. 1. Fachada principal del Colegio de San Pedro y San Pablo, Alcalá de Henares (1508-1511). Fuente: Fotografía de Raimundo Pastor.

guiente, ya que se concluyó en $1511^{24}$. Durante el curso académico 1508-1509, bajo el nombre de "cuarto de los frailes", ya estaba funcionando, y el 22 de julio de 1509 ya contaba con su fisonomía de "casa de estudiantes". Cuentas inmediatamente posteriores señalan que la casa estaba terminada incluyendo la azotea, de modo que a finales de 1510 ya se podía habitar en la pequeña edificación del colegio franciscano $^{25}$. Se sabe que tenía huerta, jardín ${ }^{26}$, una estancia "de la cátedra", refectorio, biblioteca, patios, habitaciones, cocina y una pequeña capilla provista de diversos retablos, de los que solo se conocen pequeñas referencias ${ }^{27}$. Poste-

24 GONZÁLEZ RAMOS, Roberto, La Universidad de Alcalá... opus. cit., p. 59.

25 VALLE MARTÍN, José Luis, Colegios menores seculares de la Universidad de Alcalá, Universidad de Alcalá de Henares, Servicio de Publicaciones, Alcalá de Henares, 2012, p. 19.

26 RUIZ RODRÍGUEZ, José Ignacio, "Las fundaciones... opus. cit., p. 126.

27 GARCÍA ORO, José, La Universidad de Alcalá de Henares en la etapa fundacional (1458-1578), Independencia Editorial, Santiago de Compostela, 1992, pp. 399403. riormente, el edificio debió sufrir transformaciones arquitectónicas importantes, ya que en 1532 las autoridades de la Orden Seráfica lo creyeron poco adecuado, proponiendo su reparo o reconstrucción. Lo más probable es que la sede del colegio sufriera obras y reparaciones de las que no constan noticias ${ }^{28}$. Entre $1617 \mathrm{y}$ 1620 , se llevarian a cabo otras intervenciones $^{29}$, y según las noticias que aporta Uribe, en 1673 el colegio pasaría por una profunda intervención arquitectónica que incluyó la capilla, pudiéndose incluso hablar de una reconstrucción, como indican Garay y Alcolea, trasladándose a su Capilla el Santísimo Sacramento con la asistencia a la solemnidad del Reverendísimo P. General Fr. Joseph Ximénez Samaniego, que

GONZÁLEZ RAMOS, Roberto, La Universidad de Alcalá... opus. cit., pp. 59-60.

28 URIBE, Ángel, Colegio y colegiales... opus. cit., p. 25.

29 CASTILLO OREJA, Miguel Ángel, El Colegio Mayor de San Ildefonso de Alcalá de Henares. Génesis y desarrollo de su construcción, Siglos XV-XVIII, Edascal, Madrid, 1980, doc. 27. 
dijo la Misa y el M. R. P. Provincial, Fr. Juan Romano, ambos "hijos" de dicho colegio ${ }^{30}$.

Por lo tanto, la imagen actual del Colegio de San Pedro y San Pablo es fundamentalmente -por lo que sabemos- de finales del siglo XVII, tras la citada reconstrucción de la iglesia y del torreón en una de sus esquinas. A través de su fachada principal, hoy se accede al primero de los tres patios consecutivos que estructuran la edificación, la cual limita en su frente por la Plaza de San Diego y en sus laterales por el propio Colegio Mayor y la actual calle de San Pedro y San Pablo, antigua callejuela de San Bernardo. Posee dos alturas comunicadas entre sí por una escalera imperial situada entre el segundo y primer patio, que cuenta con una galería en la planta baja de arcos de medio punto sobre columnas de granito. Los patios restantes ofrecen una factura más sencilla, sin galería, con fábrica de ladrillo y con huecos adintelados. No obstante, como es bien sabido, no existía en origen y, al parecer, desde su misma fundación, una entrada directa desde la calle para esta edificación, siendo necesario acceder al colegio menor franciscano por el patio principal del Colegio Mayor de San Ildefonso, algo que causaría problemas como se verá más adelante. La función del colegio finalizaría en 1836, momento en que el edificio fue adquirido por particulares, convirtiéndose posteriormente en propiedad de la Sociedad de Condueños ${ }^{31}$.

\section{La portada principal del Colegio de San Pedro y San Pablo}

El 26 de febrero de 1799 el alcaide de la Real Universidad de Alcalá de Henares, Víctor Fernández de la Raya, se dirigió al comisionado regio, D. Juan de Lucas y López, exponiendo que se habían producido una serie de daños en el edificio del antiguo Colegio de San Ildefonso. Dichos daños se dieron por el hecho de que las puertas principales del mismo se mantenían

30 GARAY, Manuel, Compendio chronológico, con nuevas adiciones, a la Primera Parte de la Chronica de la Santa Provincia de Burgos, Pamplona, 1742, p. 197.

ALCOLEA, Nicolás Aniceto, Seminario de Nobles, taller de Venerables y Doctos, el Colegio Mayor de San Pedro y San Pablo, fundado en la Universidad de Alcalá de Henares, Manuel Martín, Madrid, 1777, p. 307.

URIBE, Ángel, Colegio y colegiales... opus. cit., p. 26.

31 AA.VV. La Universidad de Alcalá. Colegio de Arquitectos de Madrid, Universidad de Alcalá de Henares, Alcalá de Henares, 1990, pp. 185-186. abiertas en los días no lectivos para permitir la entrada de los colegiales de la orden seráfica a través de los patios y comunicaciones de la Universidad al Colegio de San Pedro y San Pablo, debido al ya mencionado acceso obligatorio al edificio franciscano por el antiguo Colegio Mayor. Por ese motivo, se ideó como remedio dotar de una entrada al colegio franciscano desde el exterior ${ }^{32}$.

Ese mismo día, el cancelario de la Universidad, D. Pedro de la Torre y Herrera, expuso a D. Juan de Lucas que los gastos en reparos en el edificio eran continuos por la misma razón que la que señalaba el alcaide universitario, si bien desde el traslado de la Universidad al inmueble del Mayor de San Ildefonso había procurado la conservación de aulas, oficinas y demás partes de la edificación mediante puertas y la disposición de guardias en los patios. Por ello, pidió consentimiento para ejecutar las obras necesarias para remediar este asunto ${ }^{33}$.

Al día siguiente, Juan de Lucas reconoció la necesidad de abrir una puerta principal en el colegio franciscano para el uso de la comunidad sin la necesidad de atravesar la Universidad, y así poder cerrar sus puertas los días no lectivos, evitando los daños que se venían denunciando y el peligro existente de "quebrantamiento de puertas y robo de su biblioteca, monetario, archivo, contaduría y secretaría”. Para la nueva puerta, que debería ser colocada en principio a los pies de la iglesia o capilla del Colegio de San Pedro y San Pablo, se harían unas llaves que custodiarían su guardián y el alcaide de la Universidad.

Inmediatamente, el 28 de febrero de 1799, D. Juan de Lucas dio las correspondientes órdenes al casero menor de la Universidad, José Lorenzo, y mandó ejecutar dicho acceso en el lugar señalado por el cancelario y poner cerraduras en las hojas de las puertas principales del colegio franciscano "que caen al patio principal de escuelas" de la Universidad, debiendo ejecutarse las obras con el mayor decoro y solidez. Días más tarde, el 6 de marzo, el maestro mayor de obras de la Universidad, Antonio Juana Jordán, compareció ante la contaduría afirmando que había visto y reconocido los lugares del Colegio de San Pedro y San Pablo donde se podía abrir y colocar la portada, indicando además la po-

\footnotetext{
AHN. Universidades, Libro 177, fol. 397r y v.

33 Los datos que siguen proceden de la misma fuente, fol. 398r-428r.
} 
sibilidad de que hubiera otra puerta menor que comunicara con la callejuela de San Bernardo, pero resultando la principal mirando a la Plaza de San Diego, a un costado de la fachada principal de la Universidad. La portada debería ser "de piedra, con sus batientes, jambas, hermosa y con un decoro correspondiente con la Iglesia del Colegio Mayor de San Ildefonso, que se encuentra al otro lado de la fachada de la Universidad". Con el beneplácito de D. Juan de Lucas, Antonio Juana Jordán inició el plan de obra.

Durante la Semana Santa de dicho año, según comunicaba el alcaide universitario Víctor Fernández de la Raya al comisionado regio, las puertas principales de la Universidad permanecieron cerradas con el fin de contener los daños que se habían venido experimentando. Sin embargo, denunciaba que, en el segundo patio, donde se hallaban las cátedras de Filosofía y otras oficinas, "siendo forzoso tener francas las puertas" para el paso de entrada y salida de los colegiales de San Pedro y San Pablo, se había congregado un elevado número de personas. Siendo en su mayoría "de muy poca obligación y vagos", se congregaban "en diversas partidas" y "versaban diferentes juegos, siendo sus sones continuos, muy perjudiciales y escandalosos, llegando a tal el atrevimiento de violentar las puertas de las cátedras para facilitarse más satisfacción (...)", quebrando vidrieras, apedreando puertas y ventanas e incluso a D. Pedro Celestino Peralta, alcaide encargado de la cancela escolar, hiriéndole de consideración en la cabeza. Por este motivo, se insistía en la necesidad de tener cerrado el segundo patio durante los días no lectivos, al igual que el primero y tercero, para así evitar las citadas vejaciones. Con este panorama, la necesidad de la portada y nuevo acceso al colegio franciscano era evidente y su realización urgente. El 13 de abril, el casero menor, José Lorenzo, comparecía ante el comisionado real, informando de haber colocado y puesto corrientes las puertas secundarias del edificio del antiguo Colegio Mayor en la callejuela de San Bernardo, poniendo las llaves en poder del cancelario, quien se las pasó al guardián, una medida de urgencia provisional para el acceso a su colegio. Con motivo de la apertura de las nuevas puertas al colegio franciscano, se procedió al cierre y tabique de la antigua que comunicaba con el antiguo Colegio Mayor, formando un pequeño cuarto y posibilitando el cierre del patio de continuos para evitar los daños, perjuicios, juegos y malas compañías que se venían denunciando.

Por fin, el 12 de abril de 1799, Antonio Juana Jordán estableció las condiciones para ejecutar la portada de sillería para el Colegio de San Pedro y San Pablo, adjuntando su diseño en el folio 406 del documento, con pitipié o escala (Fig. 2). Las condiciones conservadas en la sección de Universidades del Archivo Histórico Nacional de Madrid se refieren, como es habitual en estos casos, a múltiples detalles técnicos relacionados con la obra. En primer lugar, se señala que la piedra a utilizar debía proceder de las canteras de Redueña, "de buena calidad, sin pelos, venteaduras ni coceras, sino sólida, tersa y limpia". Las jambas debían ser "de doce pies y medio de largo por dos de tizón, y uno y tres quartos, enterizas y limpias", estando el friso dividido en tres partes iguales, al igual que el dintel con la inclusión de una dovela en el centro que serviría de clave, detalle formal que luego se comentará con más detalle. La puerta estaría coronada por una cornisa con un vierte-aguas que también estaría despiezado en tres

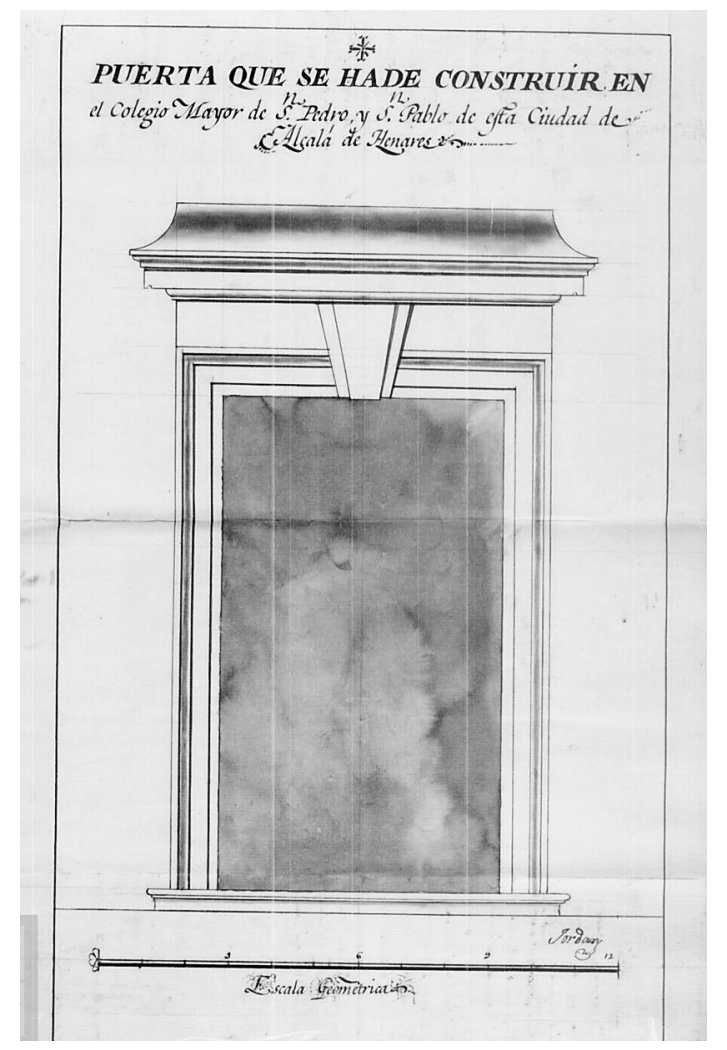

Fig. 2. Antonio Juana Jordán. Diseño de la Portada del Colegio de San Pedro y San Pablo, Alcalá de Henares (1799). Fuente: AHN. Universidades, L. 177. 
partes iguales, llevando "dos pies de tirón y la altura y vuelos que demuestra en el diseño". Los perfiles y molduras del diseño deberían estar "labradas, escodadas y atrincheradas con arreglo a buena arquitectura", y "los apeos, umbralados y rompimientos que se ofrezcan en sus paredes, como también el acompañado y guarnecido, capialzados y guarniciones de los extremos, asiento de peldaño y demás que se ofrece en el diseño”. Era condición, además, que la colocación de "los andamios, trócolas, maromas y demás pertrechos necesarios a excepción de las maderas de los umbralados y apeos" fueran a cuenta de la Universidad, quedando como obligación de a quien se adjudicara la obra devolverlas a dicha institución. Asimismo, en el caso de que el arquitecto de la Universidad considerara necesario levantar "la reja", elevándola en altura o poniendo otra más pequeña, sería obligación "del en quien rematase el ejecutarlo". Esta reja debe corresponderse con la existente en la ventana que hoy se conserva sobre la portada.

La hechura de la obra se sacó a subasta pública, de modo que aquellos candidatos que quisieran presentar su pliego bajo las condiciones anteriormente expuestas, debieron acudir a la contaduría de la Universidad en un plazo de nueve días a partir del 15 de abril de 1799 , ya que pasado dicho tiempo se procedería a la elección del cantero que la ejecutaría. Los pliegos presentados fueron cinco, en concreto de los profesores del arte de la cantería Juan Cubria (que realizaría la obra por siete mil reales de vellón), Ignacio Marín Forero (siete mil ochocientos reales de vellón), Pedro Canima firmado a ruego de José Benavente (once mil reales de vellón), Julián Cabada (cinco mil seiscientos reales de vellón) y Joaquín Castanedo, (seis mil setecientos reales de vellón). El elegido fue Julián Cabada, pues a opinión de Antonio Juana Jordán, el pliego era el más equilibrado, y cobraría el precio propuesto en tres plazos, siendo el primero la fianza, el segundo cuando la piedra estuviera al pie de la obra, y el tercero cuando la obra contara con el beneplácito del arquitecto, tal y como indicaba el mismo Cabada en su pliego.

La obra de la portada fue realizada en los términos previstos, de forma que el 2 de septiembre de 1799, Julián Cabada solicitaba que el arquitecto reconociera el resultado. Juana Jordán compareció ese mismo día y dio fe de la buena y fiel ejecución y arreglo al diseño y condiciones de la obra sin ningún tipo de reparo. Al día siguiente, el cantero Cabada recibía su último pago tal y como se había acordado, quedando así la portada terminada y el asunto que motivó su encargo zanjado. Respecto a las puertas propiamente dichas, Pedro Carrasco, carpintero de la ciudad de Alcalá, realizó "un par de puertas con sus dos postigos modados y enrasados" para el interior del colegio frente a la callejuela de San Bernardo, de 3,50 metros de alto por 2,43 de ancho, y otro par para la portería del colegio de similares características. Cabe añadir que dicho carpintero trabajó años antes en la ya citada sillería de claustro de la Real Universidad, junto a Eugenio Alonso ${ }^{34}$. Por otro lado, la cuenta de la obra de cerrajería para las puertas, firmada por Saturnino Paredes, refleja un gasto de 1.266 maravedíes, incluyendo fallebas, cerraduras, pasadores, escuadras, llamadores, tiradores y picaportes ${ }^{35}$. De este modo, el 23 de septiembre de 1799, las llaves serían entregadas al portero Víctor Fernández de la Raya $^{36}$, habiéndose satisfecho las necesidades de la Universidad y del colegio franciscano.

La portada dibujada por Juana Jordán se corresponde con la que se puede contemplar en la actualidad (Fig. 3). Sobre un umbral de dos escalones, consiste en un vano adintelado, compuesto por arquitrabe, friso y cornisa con escocia ${ }^{37}$, es decir, con una moldura redonda y hueca ${ }^{38}$, mayor que el caveto ${ }^{39}$, que ya Vitruvio recomendaba utilizar ${ }^{40}$. Las jambas son igual de anchas que el arquitrabe, como recomienda Palladio en su tratado ${ }^{41}$. La dovela o clave que divide el friso y el dintel es un elemento que recuerda a Vignola, como se puede comprobar en las láminas de sus Reglas de los cinco órdenes de arquitectura, donde en diversos casos se presenta dicha cla-

34 Véase GONZÁLEZ RAMOS, Roberto y RUIZ CARRASCO, Jesús María, "La sillería... opus. cit., pp. 181-199.

35 AHN. Universidades, Libro 177, fol. 430r.

36 AHN. Universidades, Libro 177, fol. 424r.

37 SAN NICOLÁS, Lorenzo de, Arte y uso de arquitectura..., Plácido Barco López, Madrid, 1796, p. 55.

PALADIO, Andrés, Los quatro libros de arquitectura de Andrés Paladio, Vicentino. Traducidos e ilustrados con notas de Don Joseph Francisco Ortiz y Sanz, presbitero Imprenta Real, Madrid, láminas, X, XI, XIV, XV, XVII, XX, XXVII.

38 BAILS, Benito, Arquitectura civil, Imprenta viuda de Ibarra, Madrid, 1802, p. 42.

39 BAILS, Benito, Arquitectura... opus. cit., p. 22. Moldura redonda y hueca que forma un cuadrante de círculo.

40 VITRUVIO, Marco, Los diez libros de Arquitectura, Alianza Forma, Madrid, 1997, p. 104.

${ }^{41} \quad$ PALADIO, Andrés, Los quatro libros... opus. cit., p. 35. 


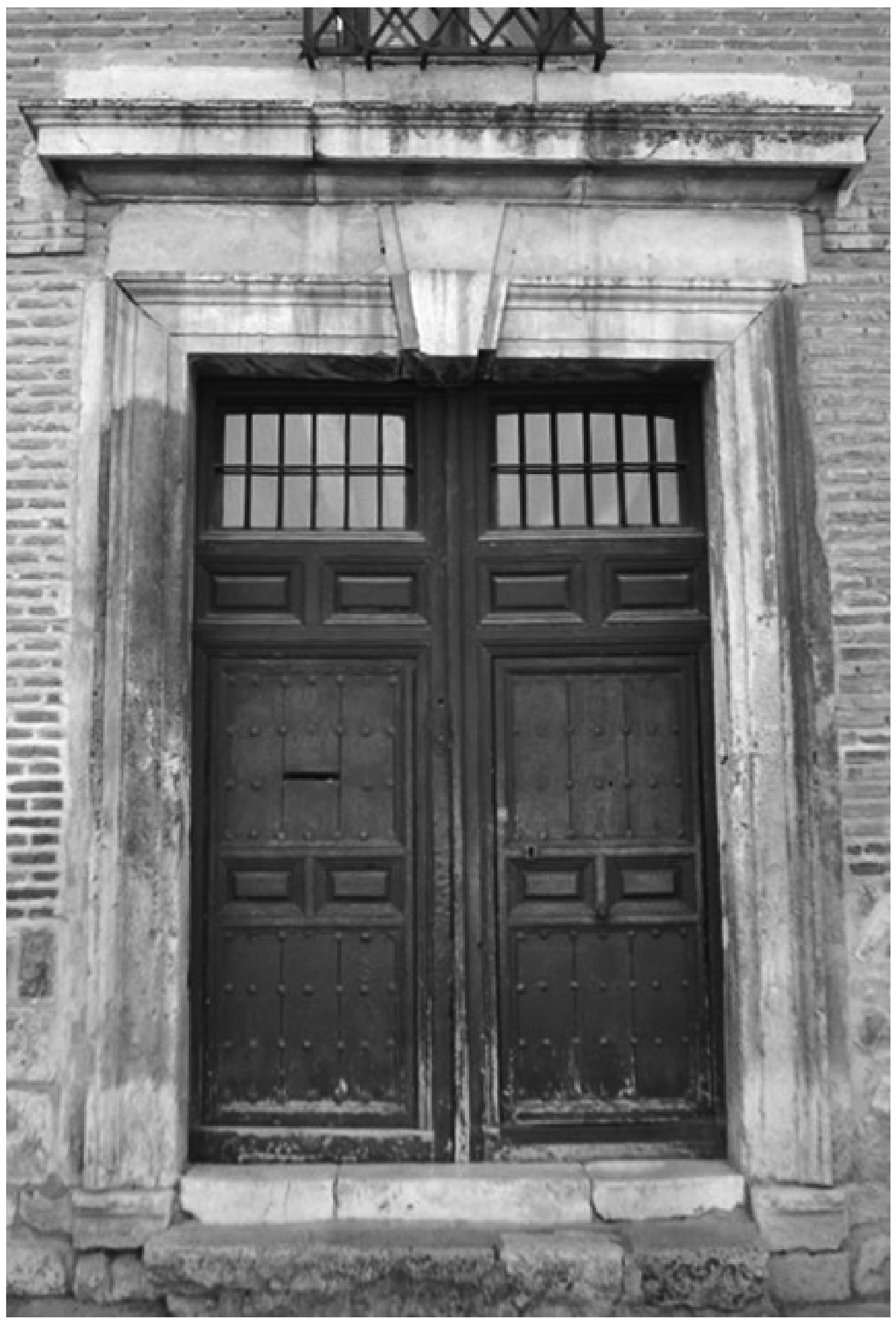

Fig. 3. Antonio Juana Jordán. Portada del Colegio de San Pedro y San Pablo, Alcalá de Henares (1799). Fuente: Fotografía del autor. 
ve con un comportamiento similar ${ }^{42}$, detalle que también pudiera haberse tomado de Palladio, cuyo tratado había sido traducido y publicado en España dos años antes de la realización de esta portada. A pesar de que su uso pudiera estar sancionado por la autoridad de estos tratadistas recientemente editados por la Academia, es una anomalía de raigambre manierista que habrá que explicar por la necesidad de dotar de mayor prestancia y dignidad a una portada que, de lo contrario, hubiese resultado excesivamente sobria y seca. Así, aunque la portada debía ajustarse a unos criterios estrictos debidos a las dificultades económicas de la Universidad en aquella época, el arquitecto le añadió este detalle, siendo un elemento que venía a completar el nuevo acceso en la línea de la fachada y del nivel de su arquitectura. En definitiva, salvo por ese detalle, se trata de una portada sencilla de cánones clásicos y académicos que satisfizo la ya mencionada necesidad de crear un acceso externo al Colegio de San Pedro y San Pablo, evitando con ella los incidentes que venían sucediéndose en la Universidad.

\section{Apéndice documental}

(Archivo Histórico Nacional, Sección de Universidades, Libro 177, fol. 410r.)

Condiciones por las quales se debe ejecutar la portada de Sillería en el Colegio de S.n Pedro y S.n. Pablo de esta ciudad de Alcalá de Henares.

$1^{a}$ Que la Piedra de Sillería que se ha de gastar en dicha Obra ha de ser de las canteras de Redueña, de buena calidad, sin pelos, veteaduras, ni coceras, sino sólida, tersa y limpia

$2^{a}$ Que las jambas hayan de ser de doce pies $y$ medio de largo por dos de tizón, y uno y tres quartos, enterizas, y limpias, y el friso haya de ir despezado en tres partes iguales, y lo mismo el dintel con inclusión de la dovela de en medio, que sirve de clave a dichos dintel y friso

$3^{a}$ Que la cornisa que corona dicha puerta con el vierte-aguas también deberá ser despezado en tres partes iguales, tanto la cornisa como dicho vierteaguas; $y$ deberán llevar dos pies y medio de tizón y la altura y vuelos que demuestra el diseño que acompaña a estas condiciones

$4^{a}$ Que hayan de llevar todos los perfiles y molduras que demuestra el Plan, labradas, escodadas, y atrincheradas con arreglo a buena arquitectura

$5^{a}$ Que se han de hacer los apeos, umbralados, y rompimientos que se ofrezcan en sus paredes, como también el acompañado y guarnecido, capialzados y guarniciones de los extremos, asiento de peldaño, y demás que se ofrezca en dicha puerta

$6^{a}$ Es condición que también haya de poner los andamios, trócolas, maromas, y demás peltrechos necesarios, a excepción de las maderas de los umbralados, y apeos, que estas serán de quenta de la (fol. 410 v) Real Unibersidad quedando de la obligación de aquel a quien se adjudique la Obra devolverlas a dicha Real Unibersidad

$7^{a} Y$ asimismo si fuese necesario levantar la reja, subirla más alta, o poner otra más pequeña según convenga y se mande por el Arquitecto de la Universidad, ha de ser obligación del en quien rematase el ejecutarlo

Concuerdan con las condiciones originales que se hallan en su Expediente a que me remito. Alcalá quince de Abril de mil setecientos noventa y nueve

Thomás María Camilo Sanz (rubricado)

42 DELAGARDETTE, C. M., Reglas de los cinco órdenes de arquitectura de Vignola, con un orden dórico de Posidonia y un apéndice que contiene las lecciones elementales de las sombras en la Arquitectura, demostradas por principios naturales, Imprenta de Manuel González, Madrid, 1792, Est. 38 y 41. 